\title{
A published
}

\section{pharmacogenetic algorithm}

was poorly predictive of

tacrolimus clearance in an independent cohort of renal transplant recipients

Oliver Boughton, ${ }^{1}$ Gabor Borgulya, ${ }^{2}$ Maurizio Cecconi, ${ }^{3}$

Salim Fredericks, ${ }^{4}$ Michelle Moreton-Clack ${ }^{5}$ \& lain A. M. MacPhee ${ }^{1}$

${ }^{1}$ Division of Clinical Sciences: Renal Medicine, St George's, University of London, London, UK, ${ }^{2}$ Clinical

Trials Unit, St George's, University of London, London, UK, ${ }^{3}$ Department of General Intensive Care, St

George's Hospital, London, UK, ${ }^{4}$ Universiti Brunei Darussalam, PAP Rashidah Sa'adatul Bolkiah

Institute of Health Sciences, Brunei, Darussalam and ${ }^{5}$ Analytical Services International, Ltd, St George's,

University of London, London, UK
Correspondence

Dr lain A. M. MacPhee DPhil, FRCP, St

George's, University of London, Division of

Clinical Sciences: Renal Medicine, London

SW17 ORE, UK.

Tel.: +442087255035

Fax: +44 2087255036

E-mail: imacphee@sgul.ac.uk

\section{Keywords}

dosing algorithm, immunosuppression, pharmacogenetics, renal transplant, tacrolimus

\section{Received}

23 May 2012

Accepted

29 December 2012

Accepted Article

Published Online

11 January 2013

\section{WHAT IS ALREADY KNOWN ABOUT THIS SUBJECT}

- Tacrolimus has a narrow therapeutic index and there is wide intra- and interpatient variability in its pharmacokinetics.

- An algorithm based on the CYP3A5 genotype to predict tacrolimus clearance to inform the optimal initial dose was derived using data from the DeKAF study (Passey et al. Br J Clin Pharmacol 2011; 72: 948-57) but was not tested in an independent cohort of patients.

\section{WHAT THIS STUDY ADDS}

- The DeKAF algorithm was unable to predict the estimated tacrolimus clearance accurately based on real tacrolimus doses and blood concentrations in our cohort of patients.

- Other genes are known to influence the clearance of tacrolimus, and a polygenic algorithm may be more predictive than those based on a single genotype.

\section{AIMS}

An algorithm based on the CYP $3 A 5$ genotype to predict tacrolimus clearance to inform the optimal initial dose was derived using data from the DeKAF study (Passey et al. Br J Clin Pharmacol 2011; 72: 948-57) but was not tested in an independent cohort of patients. Our aim was to test whether the DeKAF dosing algorithm could predict estimated tacrolimus clearance in renal transplant recipients at our centre.

\section{METHODS}

Predicted tacrolimus clearance based on the DeKAF algorithm was compared with dose-normalized trough whole-blood concentrations (estimated clearance) on day 7 after transplantation in a single-centre cohort of 255 renal transplant recipients.

\section{RESULTS}

There was a weak correlation $(r=0.431)$ between clearance based on dose-normalized trough whole-blood concentrations and DeKAF algorithm-predicted clearance. The means of the tacrolimus clearance predicted by the DeKAF algorithm and the estimated tacrolimus clearance based on the dose-normalized trough blood concentrations were plotted against the differences in the clearance as a Bland-Altman plot. Logarithmic transformation was performed owing to the increased difference in tacrolimus clearance as the mean clearance increased. There was a highly significant systematic error $(P<$ $0.0005)$ characterized by a sloped regression line [gradient, $0.88(95 \%$ confidence interval, $0.75-1.01)$ ] on the Bland-Altman plot.

\section{CONCLUSIONS}

The DeKAF algorithm was unable to predict the estimated tacrolimus clearance accurately based on real tacrolimus doses and blood concentrations in our cohort of patients. Other genes are known to influence the clearance of tacrolimus, and a polygenic algorithm may be more predictive than those based on a single genotype. 


\section{Introduction}

Tacrolimus has a narrow therapeutic index and there is wide intra- and interpatient variability in its pharmacokinetics [1]. Therapeutic drug monitoring is employed in clinical practice to monitor tacrolimus whole-blood trough concentration in renal transplant recipients [2,3]. The clearance rate of tacrolimus in individual patients can be estimated from the ratio of the tacrolimus whole-blood trough concentration to the tacrolimus dose [4]. Some studies have suggested using limited sampling techniques to estimate the area under the curve rather than a single trough concentration. When two or more measurements of tacrolimus blood concentration are taken, they may better predict the area under the curve and may therefore better predict tacrolimus clearance $[1,5,6]$. However, taking more than one blood sample a day for tacrolimus concentration may expose patients to more frequent venepuncture and is expensive. Therapeutic drug monitoring is a reactive strategy, and many patients are either underexposed to tacrolimus during the first week after the transplant, with risk of immunological rejection, or are overexposed, with the potential for toxicity. Individualization of the starting dose to the optimal dose for a given patient, rather than the current weight-based algorithm, has the potential to improve outcomes.

Tacrolimus clearance in renal transplant recipients has been shown to be influenced by pharmacogenetics [7]. It has been postulated that genetics could explain up to $39 \%$ of the variability in tacrolimus clearance [8]. The CYP3A5 and $A B C B 1$ (MDR-1) single-nucleotide polymorphisms have been most extensively studied. Tacrolimus is metabolized in the intestines and liver by the cytochrome P450 $3 \mathrm{~A} 4$ and $3 \mathrm{~A} 5$ enzymes (CYP3A4 and CYP3A5, respectively). The wild-type allele CYP3A5*1 predicts CYP3A5 expression. Homozygocity for the mutant allele $\mathrm{CYP} 3 \mathrm{~A} 5^{*} 3$ prevents expression of the CYP3A5 enzyme [9].The bioavailability of tacrolimus is also affected by the efflux transporter, P-glycoprotein. P-Glycoprotein is present in a number of tissues, including the kidney, biliary canalicular cells, lymphocytes, the intestine, brain and testis. The $A B C B 1$ gene (also known as the multidrug-resistance or MDR-1 gene) single-nucleotide polymorphisms have been shown to influence P-glycoprotein expression and tacrolimus bioavailability $[10,11]$.

Single-nucleotide polymorphisms of CYP3A5 have been clearly shown to influence the clearance of tacrolimus $[4,12]$. In patients who are CYP3A5 expressers (at least one CYP3A5*1 allele), it has been shown that tacrolimus clearance is increased compared with CYP3A5 non-expressers (CYP3A5*3 homozygotes) [10, 12-17]. $A B C B 1$ (MDR-1) single-nucleotide polymorphisms have not consistently been shown to influence the clearance rate of tacrolimus significantly $[11,14,15,18,19]$. Other genes have also been shown to influence tacrolimus clearance, including the CYP3A4*22 single-nucleotide polymor- phisms [20] and a single-nucleotide polymorphism of the gene encoding for P450 oxidoreductase $\left(P O R^{*} 28\right)$ [21].

Based on the dosing recommendations of Haufroid et al. [22], Thervet et al.carried out a randomized controlled trial to compare dosing tacrolimus for patients based on their CYP3A5 genotype with the standard practice of dosing tacrolimus based on the patient's bodyweight [23]. In their study, tacrolimus was started at day 7 , and patients were randomized to receive an individualized dose based on their CYP3A5 genotype or the standard dose based on bodyweight. They found that significantly more patients were within the target tacrolimus blood concentration window 3 days after starting treatment with CYP $3 A 5$ genotype-individualized dosing. However, the improvement was modest, from 29 to $43 \%$. While there was no difference in clinical outcome owing to aspects of the study design, it did show that there may be a role for genotype-based tacrolimus dosing $[3,23]$. In addition to genetics, the patient's age, bodyweight, ethnic group, current medications, haemoglobin concentration, haematocrit, plasma albumin concentration and day posttransplant have all been suggested as being potential causes for the variation in tacrolimus clearance rates between individuals $[4,8,10]$. Given the limited benefit of a dosing algorithm based only on the CYP $3 A 5$ genotype, attempts have been made to develop more sophisticated algorithms incorporating other parameters.

Passey et al. published a dosing model for tacrolimus in renal transplant patients that used both genetic and clinical factors [4]. Data from patients in the Deterioration of Kidney Allograft (DeKAF) Genomics study were analysed. The study assessed how tacrolimus clearance was influenced by both genetic and clinical factors. Using regression analysis, they found that tacrolimus clearance was significantly influenced by day post-transplant, CYP $3 A 5^{*} 1 /{ }^{*} 3$ genotype, transplantation at a steroidsparing centre, recipient age and calcium channel blocker use. They found that other factors, such as sex, ethnic group and bodyweight, did not have a statistically significant influence on tacrolimus clearance. They built a model that could predict tacrolimus clearance using the factors that had a statistically significant influence on tacrolimus clearance. From the predicted clearance calculated for that patient, a starting dose of tacrolimus could be recommended [4]. Their algorithm was not tested in an independent patient population. Our aim was to test the tacrolimus dosing algorithm from the DeKAF study in an independent cohort of renal transplant recipients at our centre.

\section{Methods}

We collected data from a cohort of 255 renal transplant recipients from a single centre. We had written consent for genetic testing from all patients in the study and ethics 
committee approval from the Wandsworth Research Ethics Committee for genetic testing. Predicted tacrolimus clearance based on the DeKAF algorithm was compared with dose-normalized trough whole-blood concentrations (estimated clearance) on day 7 after transplantation. The final dosing equation published by Passey et al. [4] is shown below:

Clearance $(C L / F$; in litres per hour $)=38.4 \times[(0.86$, if days $6-10)$ or $(0.71$, if days $11-180)] \times\left[\left(1.69\right.\right.$, if $C Y P 3 A 5^{*} 1 /^{*} 3$ genotype) or $\left(2.00\right.$, if CYP3A $55^{*} 1 /{ }^{*} 1$ genotype $\left.)\right] \times(0.70$, if receiving a transplant at a steroid-sparing centre) $\times$ (age in years $\left./ 50)^{-0.4}\right) \times(0.94$, if calcium channel blocker present).

We collected data at day 7 post-transplantation, and our patients were all on steroids at day 7 . We collected the following data: age at transplant, sex, ethnic group, CYP3A5 genotype, tacrolimus dose at day 7 (range, days 6-8), tacrolimus whole-blood trough concentration at day 7 (range, days 6-8) and whether they were taking a calcium channel blocker at the time of transplant. For every patient, we calculated the predicted tacrolimus clearance using the DeKAF algorithm. We also calculated the estimated real clearance for every patient (the dose-normalized wholeblood trough concentration). This was calculated by the following equation: estimated real clearance (in litres per hour) $=$ (daily tacrolimus dose (in milligrams) at day 7 posttransplant/24)/[trough whole-blood concentration (in nanograms per millilitre) at day 7 post-transplant] $\times 1000$. This equation was derived from the following equation in the paper by Passey et al.: $C_{\text {obs }}=$ dosing rate/(CL/F), where $C_{\text {obs }}$ was the observed tacrolimus trough concentration and dosing rate was the total daily dose of tacrolimus (in milligrams) divided by $24 \mathrm{~h}$ [4].

We compared the DeKAF algorithm-predicted clearance and the dose-normalized whole-blood trough concentration-estimated clearance for every patient. Initially, this was done using a scatter plot and assessing correlation between the two measurements. We then used the Bland-Altman method to assess agreement between two clinical measurements [24]. We used regression analysis to determine whether the algorithm could be modified to more accurately predict clearance in our cohort of patients. We used the statistical software $\mathrm{IBM}^{\circledR}$ SPSS ${ }^{\circledR}$ Statistics 19. We analysed the following covariates: CYP3A5 genotype, age, the use of a calcium channel blocker at the time of transplantation, bodyweight, sex and ethnic group (either Black or non-Black).

The target $12 \mathrm{~h}$ postdose (trough) whole-blood concentration for our cohort on day 7 after transplantation was 8-20 $\mathrm{ng} \mathrm{ml}^{-1}$, with a tendency to aim at lower exposure in more recently transplanted patients. All patients were treated with steroid for at least 7 days, as follows: $500 \mathrm{mg}$ methylprednisolone intravenously at surgery; then $20 \mathrm{mg}$ prednisolone once daily. Prednisolone was either discontinued after 7 days or reduced by $5 \mathrm{mg}$ every 2 weeks to a maintenance dose of $5 \mathrm{mg}$ once daily. In addition, 46 patients were treated with azathioprine and
75 with mycophenolate mofetil. Azathioprine and mycophenolate mofetil are not known to interact significantly with the pharmacokinetics of tacrolimus [19]. The tacrolimus whole-blood trough concentration was measured using immunoassay (Tacrolimus II; Abbott Diagnostics, Abbott Park, IL, USA) performed on an IMx clinical analyser (Abbott Diagnostics) (limit of detection $1.5 \mathrm{ng} \mathrm{ml}^{-1}$, total precision $<16.4 \%$ coefficient of variation [25]) until January 2005; thereafter, the EMIT 2000 Syva immunoassay (Siemens; formerly Dade-Behring) was performed on a Viva-E analyser (Abbott Diagnostics) (limit of detection $2.0 \mathrm{ng} \mathrm{ml}^{-1}$, total precision $<16.5 \%$ coefficient of variation [26]). The laboratory was a member of the International Tacrolimus Proficiency Testing Scheme. Genomic DNA was extracted from whole blood using a QIAamp DNA Mini Kit (Qiagen, Crawley, UK). Genotyping of CYP3A5 was then performed using a LightCycler (Roche Diagnostics Ltd, Lewes, UK) [12, 27].

\section{Results}

The demographics of our cohort are shown in Table 1. A scatter plot of the dose-normalized trough wholeblood concentration-estimated clearance plotted against the DeKAF algorithm-predicted clearance is shown in Figure 1. There was a weak correlation $(r=0.431$, $\left.r^{2}=0.186\right)$ between the dose-normalized trough whole-blood concentration-estimated clearance and the DeKAF algorithm-predicted clearance. The mean DeKAF algorithm-predicted clearance was $43.15 \mathrm{I} \mathrm{h}^{-1}$ (SD, 13.66; range, 19.3-60.1) and the mean dose-normalized trough whole-blood concentration-estimated clearance was $47.41 \mathrm{I} \mathrm{h}^{-1}$ (SD, 29.65; range, 5.8-196). The Bland-Altman method was used to assess agreement. The mean of the DeKAF algorithm-predicted clearance and the dosenormalized trough whole-blood concentration-estimated clearance was calculated for every patient. The difference between the clearance values was calculated by subtracting the DeKAF algorithm-predicted clearance from the dose-normalized trough whole-blood concentrationestimated clearance. The mean difference in tacrolimus clearance was $17.2 \mathrm{I} \mathrm{h}^{-1}$, and the SD of the difference was $26.89 \mathrm{I} \mathrm{h}^{-1}$ (range, -21.3 to +155.3 ). A logarithmic transformation was performed due to the increased difference in tacrolimus clearance as the mean clearance increased. The log-transformed Bland-Altman plot is shown in Figure 2. There was a highly significant systematic error $(P<0.0005)$ characterized by a sloped regression line on the BlandAltman plot [gradient of the slope $=0.88$ ( $95 \%$ confidence interval, 0.75-1.01)].

Regression analysis of the covariates from our cohort was performed to determine which factors had a significantly influence on the estimated tacrolimus clearance (dose-normalized trough whole-blood concentrationestimated clearance) in our patients. The CYP3A5 


\section{Table 1}

Patient details

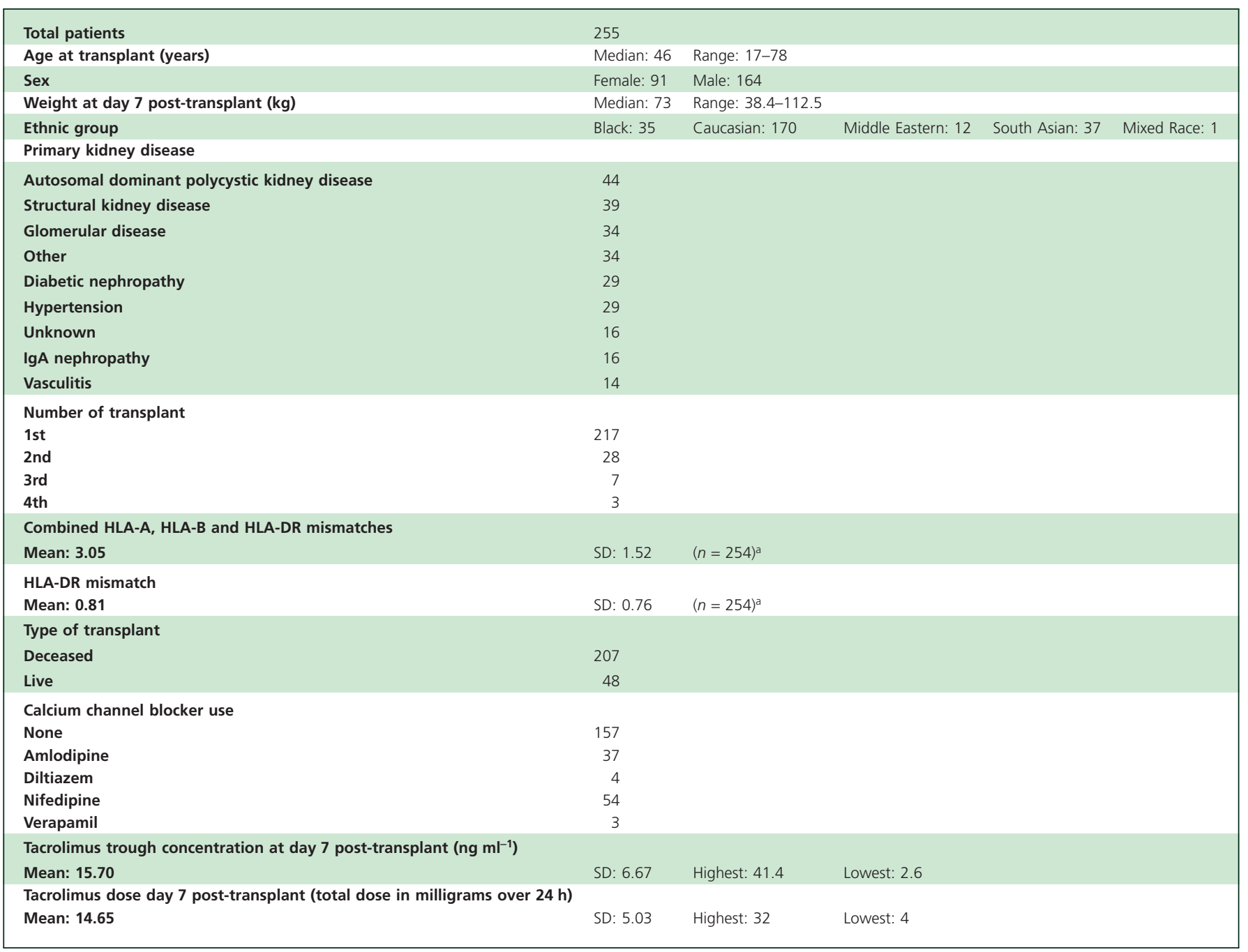

${ }^{a}$ Where incomplete data were available, the numbers available are indicated.

genotype significantly influenced tacrolimus clearance. The CYP $3 A 5^{*} 1 /^{*} 1$ genotype, when compared with the CYP $3 A{ }^{*} 3 /{ }^{*} 3$ genotype, was associated with a higher tacrolimus clearance by a factor of 1.88 ( $95 \%$ confidence interval, $1.49-2.39, P<0.0005)$. The $C Y P 3 A 5^{*} 1 /{ }^{*} 3$ genotype, when compared with the CYP3A5*3/*3 genotype, was associated with a higher tacrolimus clearance by a factor of 1.74 (95\% confidence interval, $1.50-2.02, P<0.0005$ ). Age also significantly influenced tacrolimus clearance by a factor of age in years $/ 50^{-0.312}(P=0.003)$. This means that the clearance rate was lower with increased age in our study. The presence of a calcium channel blocker did not significantly alter tacrolimus clearance. In our cohort, sex significantly influenced tacrolimus clearance. Female sex was associated with a lower tacrolimus clearance by a factor of 0.86 (95\% confidence interval, $0.76-0.99, P=$ 0.032 ). In our cohort, bodyweight did not significantly influence tacrolimus clearance $(P=0.54)$, and ethnic group (either Black or non-Black), as an independent variable also did not significantly influence tacrolimus clearance $(P=0.144)$.

\section{Discussion}

The DeKAF algorithm [4] was unable to predict the tacrolimus clearance accurately based on real tacrolimus doses and blood concentrations in our population. We directly compared estimated real tacrolimus clearance rates in our cohort of patients with predicted tacrolimus clearance rates based on genetic and clinical factors as defined in the DeKAF algorithm for dosing tacrolimus. We found that as the mean of the estimated real clearance and the predicted clearance for a patient increased, the differences between the real estimated clearance and the predicted clearance increased. This was demonstrated by a 


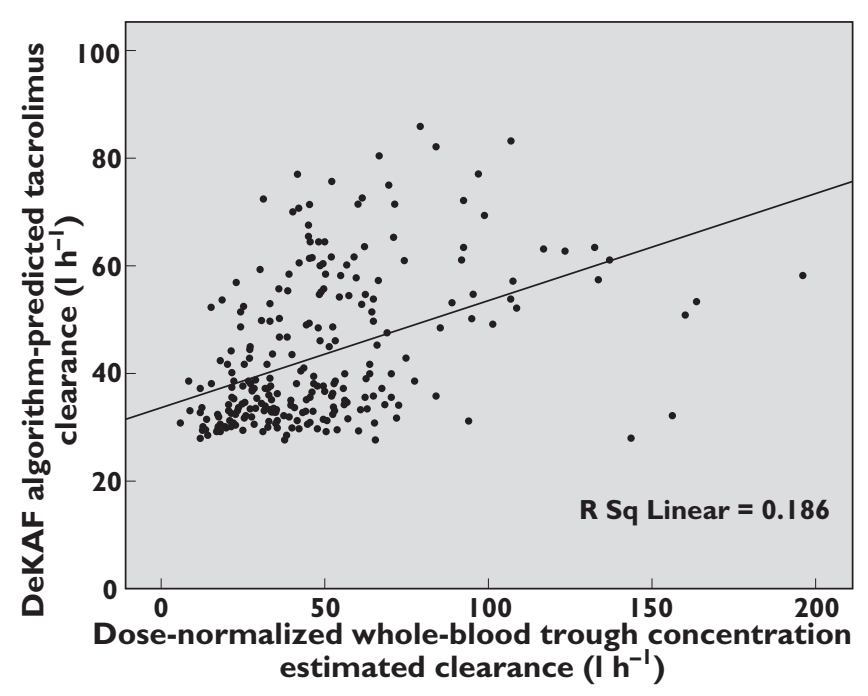

\section{Figure 1}

Dose-normalized whole-blood trough concentration estimated clearance (in litres per hour)

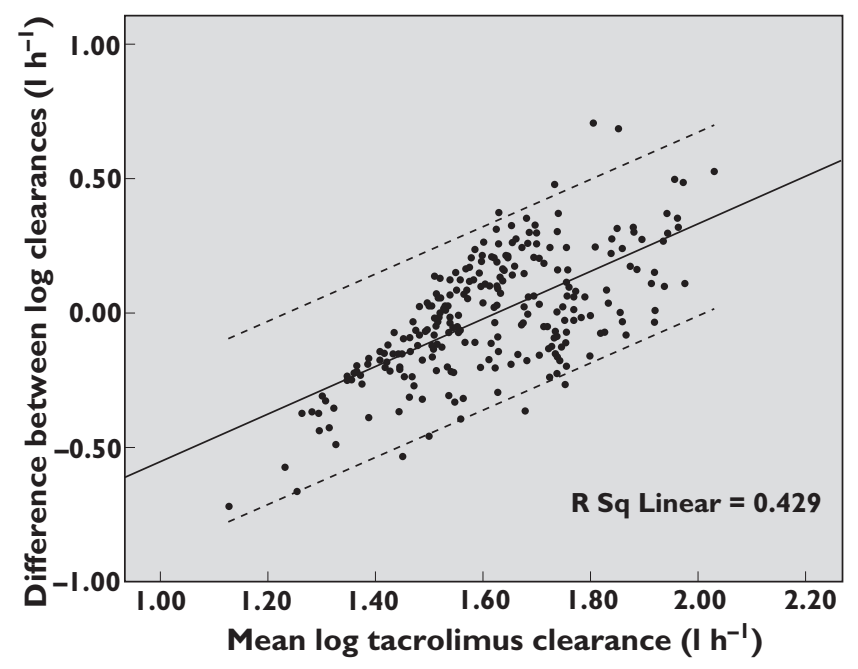

\section{Figure 2}

Mean log tacrolimus clearance (in litres per hour)

sloped regression line on a Bland-Altman plot.In the study of Passey et al. [4], the equation they used to calculate the recommended total daily dose (TDD) based on the predicted clearance is shown below:

\section{$\operatorname{TDD}$ (in milligrams) $=(C L / F$ (in litres per hour) $\times$ tacrolimus trough goal (in nanograms per millilitre) $\times 24 \mathrm{~h}$ )/1000}

In our study, the mean difference in tacrolimus clearance between the DeKAF algorithm-predicted clearance and the estimated real clearance was $17.2 \mathrm{I} \mathrm{h}^{-1}$, and the SD of the difference was $26.89 \mathrm{I} \mathrm{h}^{-1}$. Assuming that the clinician is aiming for a tacrolimus trough concentration of $12.5 \mathrm{ng} \mathrm{ml}^{-1}$, for a $17.2 \mathrm{I} \mathrm{h}^{-1}$ difference in tacrolimus clearance the difference in recommended total daily dose is $(17.2 \times 12.5 \times 24) / 1000=5.16 \mathrm{mg}$. In our cohort of patients, the influence of the CYP3A5 genotype on tacrolimus clearance rate was similar to the DeKAF study. For CYP3A5*1*3 patients, clearance was 1.74 times higher in our cohort, compared with 1.69 times in the DeKAF cohort. For $C Y P 3 A 5^{*} 1 /{ }^{*} 1$ patients, clearance was 1.88 times higher in our cohort, compared with 2.00 times in the DeKAF cohort. Age significantly influenced clearance in our cohort as well. Calcium channel blocker use significantly influenced clearance in the DeKAF cohort, but in our study it did not. This may reflect avoidance of nondihydropyridine calcium channel blockers in our cohort. We were unable to assess the influence of steroids or day post-transplant because all patients were on steroids at day 7 post-transplant in our study. When we analysed some of the factors that did not influence tacrolimus clearance significantly in the DeKAF study, we found that sex did significantly influence tacrolimus clearance, in contrast to the DeKAF study. We found that female patients had a lower clearance rate (female clearance rate $=0.86 \times$ male clearance rate). We that found ethnic group and bodyweight, as independent variables, did not statistically significantly influence tacrolimus clearance in our cohort, in agreement with the findings from the DeKAF study [4]. It is worth noting that $37 \%$ of the Black patients in our cohort had the CYP3A5 ${ }^{*} 1 /^{*} 1$ genotype, $54 \%$ had the CYP $3 A 5^{*} 1 / * 3$ genotype and only $9 \%$ were CYP3A5 nonexpressers, which may explain why ethnicity was not an independent predictor of tacrolimus dose requirement. While Black CYP3A5 non-expressers have been described to have a high dose requirement for tacrolimus, independent of CYP3A5 genotype, there were too few patients in this category to be detectable as a significant independent factor. It is known that tacrolimus clearance is higher in Black patients $[12,28]$, but this may be due to the high proportion of CYP3A5 expressers in this ethnic group. Tacrolimus assay methodology may have contributed to our discrepant findings. Immunoassay was used for our cohort, but the assay methodology was not specified for the DeKAF study.

It is clear that genetics significantly influence tacrolimus clearance rate. The influence of the CYP $3 A 5$ genotype on tacrolimus clearance was similar in our cohort and the DeKAF cohort. The DeKAF dosing algorithm was not able to predict accurately the real estimated tacrolimus clearance in our cohort, particularly when the real estimated tacrolimus clearance rate was high. We were unable to generate a better predictive model based on this data set, presumably due to influence of clinical or genetic factors that were not included in the model. A polygenic algorithm incorporating the other genes known to influence the clearance of tacrolimus, including $A B C B 1$, CYP3A4*22, POR 28 and PXR [29], may be more predictive 
of the optimal initial tacrolimus dose than those based on a single genotype.

\section{Competing Interests}

All authors have completed the Unified Competing Interest form at http://www.icmje.org/coi_disclosure.pdf (available on request from the corresponding author) and declare no support from any organization for the submitted work. I.A.M.M. has received research funding (not for the study described here), assistance with conference expenses and speaker honoraria from Astellas. There were no other relationships or activities that could appear to have influenced the submitted work.

\section{REFERENCES}

1 Op den Buijsch RAM, van de Plas A, Stolk LML, Christiaans MHL, van Hooff JP, Undre NA, van Dieijen-Visser MP, Bekers O. Evaluation of limited sampling strategies for tacrolimus. Eur J Clin Pharmacol 2007; 63: 1039-44.

2 Kahan BD, Keown IP, Levy GA, Johnston A. Therapeutic Drug Monitoring of Immunosuppressant Drugs in Clinical Practice. Clin Ther 2002; 24: 330-50.

3 van Gelder T, Hesselink DA. Dosing Tacrolimus Based on CYP3A5 Genotype: will It Improve Clinical Outcome? Clin Pharmacol Ther 2010; 87: 640-1.

4 Passey C, Birnbaum AK, Brundage RC, Oetting WS, Israni AK, Jacobson PA. Dosing equation for tacrolimus using genetic variants and clinical factors. Br J Clin Pharmacol 2011; 72: 948-57.

5 Scholten EM, Cremers SCLM, Schoemaker RC, Rowshani AT, van Kan EJ, Den Hartigh J, Paul LC, De Fijter JW. AUC-guided dosing of tacrolimus prevents systemic overexposure in renal transplant recipients. Kidney Int 2005; 67: 2440-7.

6 Barraclough KA, Isbel NM, Kirkpatrick CM, Lee KJ, Taylor PJ, Johnson DW, Campbell SB, Leary DR, Staatz CE. Evaluation of limited sampling methods for estimation of tacrolimus exposure in adult kidney transplant recipients. $\mathrm{Br} \mathrm{J}$ Clin Pharmacol 2011; 71:207-23.

7 Ware N, MacPhee IAM. Current progress in pharmacogenetics and individualized immunosuppressive drug dosing in organ transplantation. Curr Opin Mol Ther 2010; 12: 270-83.

8 Birdwell KA, Grady B, Choi L, Xu H, Bian A, Denny JC, Jiang M, Vranic G, Basford M, Cowan JD, Richardson DM, Robinson MP, Ikizler TA, Ritchie MD, Stein CM, Haas DW. The use of a DNA biobank linked to electronic medical records to characterize pharmacogenomic predictors of tacrolimus dose requirement in kidney transplant recipients. Pharmacogenet Genomics 2012; 22: 32-42.

9 Kuehl P, Zhang J, Lin Y, Lamba J, Assem M, Schuetz J, Watkins PB, Daly A, Wrighton SA, Hall SD, Maurel P, Relling M, Brimer
C, Yasuda K, Venkataramanan R, Strom S, Thummel K, Boguski MS, Schuetz E. Sequence diversity in CYP3A promoters and characterization of the genetic basis of polymorphic CYP3A5 expression. Nat Genet 2001; 27: 383-91.

10 MacPhee IAM, Fredericks S, Tai T, Syrris P, Carter ND, Johnston A, Goldberg L, Holt DW. Tacrolimus Pharmacogenetics: polymorphisms associated with expression of Cytochrome P4503A5 and P-Glycoprotein correlate with Dose Requirement. Transplantation 2002; 74 : 1486-9.

11 Li D, Gui R, Li J, Huang Z, Nie X. Tacrolimus Dosing in Chinese Renal Transplant Patients Is Related to MDR1 Gene C3435T Polymorphisms. Transplant Proc 2006; 38: 2850-2.

12 MacPhee IAM, Fredericks S, Mohamed M, Moreton M, Carter ND, Johnston A, Goldberg L, Holt DW. Tacrolimus Pharmacogenetics: the CYP3A5*1 Allele Predicts Low Dose-Normalized Tacrolimus Blood Concentrations in Whites and South Asians. Transplantation 2005; 79: 499-502.

13 de Wildt SN, van Schaik RH, Soldin OP, Soldin SJ, Brojeni PY, van der Heiden IP, Parshuram C, Nulman I, Koren G. The interactions of age, genetics, and disease severity on tacrolimus dosing requirements after pediatric kidney and liver transplantation. Eur J Clin Pharmacol 2011;67: 1231-41.

14 Gijsen V, Mital S, van Schaik RH, Soldin OP, Soldin SJ, van der Heiden IP, Nulman I, Koren G, de Wildt SN. Age and CYP3A5 genotype affect tacrolimus dosing requirements after transplant in pediatric heart recipients. J Heart Lung Transplant 2011; 30: 1352-9.

15 Glowacki F, Lionet A, Buob D, Labalette M, Allorge D, Provôt F, Hazzan M, Noël C, Broly F, Cauffiez C. CYP3A5 and ABCB1 polymorphisms in donor and recipient: impact on Tacrolimus dose requirements and clinical outcome after renal transplantation. Nephrol Dial Transplant 2011; 26: 3046-50.

16 Hesselink DA, van Schaik RH, van der Heiden IP, van der Werf M, Gregoor PJ, Lindemans J, Weimar W, van Gelder T. Genetic polymorphisms of the CYP3A4, CYP3A5, and MDR-1 genes and pharmacokinetics of the calcineurin inhibitors cyclosporine and tacrolimus. Clin Pharmacol Ther 2003; 74: 245-54.

17 Wehland M, Bauer S, Brakemeier S, Burgwinkel P, Glander P, Kreutz R, Lorkowski C, Slowinski T, Neumayer HH, Budde K. Differential impact of the CYP3A5*1 and CYP3A5*3 alleles on pre-dose concentrations of two tacrolimus formulations. Pharmacogenet Genomics 2011; 21: 179-84.

18 Zheng HX, Zeevi A, Schuetz E, Lamba J, McCurry K, Griffith BP, Webber S, Ristich J, Dauber J, lacono A, Grgurich W, Zaldonis D, McDade K, Zhang J, Burckart GJ. Tacrolimus Dosing in Adult Lung Transplant Patients is Related to Cytochrome P4503A5 Gene Polymorphism. J Clin Pharmacol 2004; 44: 135-40.

19 Fredericks S, Moreton M, Reboux S, Carter ND, Goldberg L, Holt DW, MacPhee IAM. Multidrug Resistance Gene-1 (MDR-1) Haplotypes Have a Minor Influence on Tacrolimus Dose Requirements. Transplantation 2006; 82: 705-8.

20 Elens L, Bouamar R, Hesselink DA, Haufroid V, van der Heiden IP, van Gelder T, van Schaik RH. A new functional CYP3A4 
intron 6 polymorphism significantly affects tacrolimus pharmacokinetics in kidney transplant recipients. Clin Chem 2011; 57: 1574-83.

21 De Jonge $H$, Metalidis C, Naesens M, Lambrechts D, Kuypers DRJ. The P450 oxidoreductase * 28 SNP is associated with low initial tacrolimus exposure and increased dose requirements in CYP3A5-expressing renal recipients. Pharmacogenomics 2011; 12: 1281-91.

22 Haufroid V, Wallemacq P, VanKerckhove V, Elens L, De Meyer M, Eddour DC, Malaise J, Lison D, Mourad M. CYP3A5 and $A B C B 1$ polymorphisms and tacrolimus pharmacokinetics in renal transplant candidates: guidelines from an experimental study. Am J Transplant 2006; 6: 2706-13.

23 Thervet $E$, Loriot MA, Barbier S, Buchler M, Ficheux M, Choukroun G, Toupance O, Touchard G, Alberti C, Le Pogamp $P$, Moulin B, Le Meur Y, Heng AE, Subra JF, Beaune P, Legendre C. Optimization of initial tacrolimus dose using pharmacogenetic testing. Pharmacol Ther 2010; 87: 721-6.

24 Bland JM, Altman DG. Statistical methods for assessing agreement between two methods of clinical measurement. Lancet 1986; 1: 307-10.
25 Tacrolimus II. 2007. Abbott Laboratories Diagnostic Division, Abbott, IL, 60064, USA.Phone:+1-877-4ABBOTT.

26 Syva. Emit 2000 Tacrolimus Assay. 2008. Siemens Healthcare Diagnostics Inc, 511 Benedict Avenue, Tarrytown, NY 10591, USA. Phone: +1914 631-8000.

27 Fredericks S, Moreton M, MacPhee IA, Mohamed M, Marlowe S, Jorga A, Johnston A, Carter ND, Holt DW. Genotyping cytochrome P450 3A5 using the Light Cycler. Ann Clin Biochem 2005; 42: (Pt 5): 376-81.

28 Mancinelli LM, Frassetto L, Floren LC, Dressler D, Carrier S, Bekersky I, Benet LZ, Christians U. The pharmacokinetics and metabolic disposition of tacrolimus: a comparison across ethnic groups. Clin Pharmacol Ther 2001; 69: 24-31.

29 Benkali K, Prémaud A, Picard N, Rérolle JP, Toupance O, Hoizey G, Turcant A, Villemain F, Le Meur Y, Marquet P, Rousseau A. Tacrolimus population pharmacokinetic-pharmacogenetic analysis and Bayesian estimation in renal transplant recipients. Clin Pharmacokinet 2009; 48: 805-16. 